\title{
Attribution of explanatory factors for change in soil organic carbon density in the native grasslands of Inner Mongolia, China
}

\author{
JIN Dongyan ${ }^{1}$, Phil J MURRAY ${ }^{2}$, XIN Xiaoping ${ }^{1 *}$, QIN Yifei ${ }^{1}$, CHEN Baorui $^{1}$, QING Gele ${ }^{3}$, \\ ZHANG Zhao ${ }^{1}$, YAN Ruirui ${ }^{1}$ \\ ${ }^{1}$ Institute of Agricultural Resources and Regional Planning, Chinese Academy of Agricultural Sciences, Beijing 100081, China; \\ ${ }^{2}$ Department of Sustainable Soils and Grassland Systems, Rothamsted Research, North Wyke, Okehampton, Devon EX20 2SB, \\ UK; \\ ${ }^{3}$ Department of Grassland Ecology and Animal Husbandry, Xilingol Vocational College, Xilinhot 026000, China
}

\begin{abstract}
The variation in soil organic carbon density (SOCD) has been widely documented at various spatial and temporal scales. However, an accurate method for examining the attribution of explanatory factors for change in SOCD is still lacking. This study aims to attribute and quantify the key climatic factors, anthropogenic activities, and soil properties associated with SOCD change in the native grasslands of Inner Mongolia, China, by comparing data between the 1960s and the 2010s. In 2007 and 2011, we resampled 142 soil profiles which were originally sampled during 1963-1964 in the native grasslands of Inner Mongolia. SOCD was determined in A horizon (eluvial horizon) of the soil. We selected the explanatory factors based on a random forest method, and explored the relationships between SOCD change and each of the explanatory factors using a linear mixed model. Our results indicated that the change in SOCD varied from the east to the west of Inner Mongolia, and SOCD was $18 \%$ lower in the 2010 s than in the 1960 s. The lower SOCD in the 2010 s may primarily be attributed to the increasing in mean annual water surface evaporation, which explained approximately $10 \%$ and $50 \%$ of the total variation and explainable variation in the change in SOCD, respectively. The sand content of the soil is also a significant explanatory factor for the decrease in SOCD, which explained about $4 \%$ and $21 \%$ of the total variation and explainable variation in the change in SOCD, respectively. Furthermore, the collection of quantitative information on grazing frequency and duration may also help to improve our understanding of the anthropogenic factors that govern the change in SOCD.
\end{abstract}

Keywords: soil organic carbon; climate change; soil texture; mixed linear model; effect isolation; native grasslands

Citation: JIN Dongyan, Phil J MURRAY, XIN Xiaoping, QIN Yifei, CHEN Baorui, QING Gele, ZHANG Zhao, YAN Ruirui. 2018. Attribution of explanatory factors for change in soil organic carbon density in the native grasslands of Inner Mongolia, China. Journal of Arid Land, 10(3): 375-387. https://doi.org/10.1007/s40333-018-0056-4

\section{Introduction}

Soil is the largest carbon pool in the terrestrial biosphere, containing approximately $1550 \mathrm{Pg}(1$ $\mathrm{Pg}=10^{15} \mathrm{~g}$ ) of soil organic carbon (SOC) and $950 \mathrm{Pg}$ of soil inorganic carbon (Lal, 1999; Watson and Noble, 2002; Batjes, 2014). Any changes in SOC may affect the components involved in carbon cycling of terrestrial ecosystems by influencing the atmospheric $\mathrm{CO}_{2}$ concentration and soil-derived ecosystem services (Davidson and Janssens, 2006). Thus, SOC has significant impacts on the carbon balance in terrestrial ecosystems (Davidson and Janssens, 2006; Trumbore

\footnotetext{
*Corresponding author: XIN Xiaoping (E-mail: xinxp@sina.com)

Received 2017-07-10; revised 2017-12-18; accepted 2018-01-03

C Xinjiang Institute of Ecology and Geography, Chinese Academy of Sciences, Science Press and Springer-Verlag GmbH Germany, part of Springer Nature 2018
} 
and Czimczik, 2008).

Grasslands, covering about $30 \%$ of the global land surface and storing $28 \%-37 \%$ of carbon in terrestrial ecosystems, have been confirmed to explore the potentials for carbon sequestration (Lal, 2004). As a gigantic carbon pool, grassland ecosystem plays a critical role in the global carbon cycling (Cao and Woodward, 1998). The grassland ecosystem is the largest terrestrial ecosystem in China ( $41 \%$ of the total land area), especially in Inner Mongolia Autonomous Region. Since the 1960 s, there have been enormous cultural changes in Inner Mongolia which have significantly impacted the grazing and land management in this region, leading to increasing pressures on the grassland ecosystem such as a rise in livestock numbers (increasing by $2.8 \times 10^{6}$ cattle and $3.1 \times 10^{9}$ sheep from the 1960s to the 2010s) and overgrazing. At the same time, regional climate has also changed in Inner Mongolia, with the annual mean temperature rising from $3.5^{\circ} \mathrm{C}$ to $5.1^{\circ} \mathrm{C}$ and mean annual precipitation decreasing from 320 to $272 \mathrm{~mm}$ (Hu et al., 2015). Such simultaneous changes (anthropogenic and climatic factors) can inevitably impact the SOC in the grassland ecosystem of Inner Mongolia.

SOC storage is determined by the balance between the mass of carbon inputs and outputs, which are affected by many factors, such as climate change, land use change and soil properties (Burke et al., 1989; Bai et al., 2012; Butler-Lapointe, 2014; Zhao et al., 2015). For example, desertification could reduce SOC storage by decreasing the clay content in soil (Schjønning et al., 1999), as we know that clay may improve the bonds between soil organic matter (SOM) and soil particles, protecting soil aggregates and reducing SOC leaching. Precipitation events can promote soil respiration and increase net primary productivity in temperate grasslands, resulting in the accumulation of SOC storage (Chen et al., 2004; Yang et al., 2010). Increasing temperature has an acceleration effect on SOC decomposition, especially for stable SOC loss (Davidson and Janssens, 2006; Lefèvre et al., 2014). Grazing can have profound impacts on soil properties and processes (Piñeiro et al., 2010). Since these above-mentioned factors may act simultaneously on SOC, it is difficult to quantify their relative contributions to the change in SOC at a regional scale and in a long-term scale.

There are many researches related to the estimation of SOC storage and change (e.g., Li et al., 2011; Dai et al., 2014; Conforti et al., 2016). However, the results may differ at regional scales or even at ecosystem scales (Goidts and Van Wesemael, 2007; Mestdagh et al., 2009; Fujisaki et al., 2015; Conforti et al., 2016). For the grasslands of Inner Mongolia, Xie et al. (2007) estimated a loss of $0.56 \mathrm{Pg}$ of SOC from the 1980s to the 2000s, while Dai et al. (2014) reported a slight increase of SOC storage in the topsoil $(0.12 \mathrm{Pg} \mathrm{C})$, with an increasing rate of $7 \mathrm{~g} \mathrm{C} /\left(\mathrm{m}^{2} \cdot \mathrm{a}\right)$, over the same period. The native grasslands of Inner Mongolia, located on the Eurasian Continent, are an important area for climate change research along the Northeast China transect of the International Geosphere-Biosphere Program (IGBP), since this region is extremely sensitive to climate change (Dai et al., 2014). This region is also an important livestock production area and acts as a natural green protective barrier for North China (Zhang et al., 2011). In this study, we used two advanced methods (linear mixed model (LMM; also referred to as multilevel/hierarchical model) and random forest method) to analyze the attribution of factors impacting the change of soil organic carbon density (SOCD; a major indicator of SOC storage estimation) in the native grasslands of Inner Mongolia. LMM, which is gaining attention for use in ecological data analysis, is a generalized form of the standard linear model. In the generalized form, data are permitted to exhibit correlation and non-constant variability (Goidts et al., 2009). Furthermore, LMM estimates not only the means of the data (fixed effects) but also the variance and covariance (random effects). A random forest model was used to identify the subset of non-redundant explanatory factors introduced into the LMM. The random forest method is a popular tool for classification using high-dimensional data and can rank candidate predictors via inbuilt factor importance measures (Breiman, 2001; Janitza et al., 2016).

Generally speaking, the overall objectives of this study were (1) to identify the long-term (approximately 50 years) effects of several key explanatory factors (including climate factors, anthropogenic factors and soil properties) on the change in SOCD and to (2) quantify the attributions of these explanatory factors on the change of SOCD in the native grasslands of Inner 
Mongolia.

\section{Materials and methods}

\subsection{Study area}

This study was conducted in the native grasslands of Inner Mongolia Autonomous Region $\left(38^{\circ}-51^{\circ} \mathrm{N}, 107^{\circ}-125^{\circ} \mathrm{E}\right.$; Fig. 1), China. Inner Mongolia has a temperate continental monsoon climate, with annual mean temperature ranging from $-5^{\circ} \mathrm{C}$ to $9^{\circ} \mathrm{C}$, mean annual precipitation ranging from 150 to $500 \mathrm{~mm}$, and mean annual evaporation ranging from 1200 to $2500 \mathrm{~mm}$, from the northeast to the southwest (Dai et al., 2014).

The native grasslands of Inner Mongolia consist of three ecotypes, i.e., meadow steppe, typical steppe and desert steppe. The meadow steppe ecotype, located in the east of Inner Mongolia, is mainly distributed in the transitional zone between mountain coniferous forest and steppe around the Da Hinggan Mountains. The soil associated with this ecotype is predominantly chernozem and the vegetation is characterized by perennial mesophyte and xerophyte plants, with the dominate species of Stipa baicalensis, Filifolium sibiricum and Leymus chinensis (Ma et al., 2008). The typical steppe ecotype is located at the center of Inner Mongolia, where the soil is dominated by chestnut and the vegetation is composed of typical perennial xerophyte plants, with the constructive species of Stipa grandis, Stipa kryovii, L. chinensis and Stipa bungeana. The desert steppe ecotype is distributed in the west of Inner Mongolia and exhibits brown calcic soil. The vegetation is dominated by dwarf plants with high drought resistance, such as Stipa klemenzii, Stipa glareosa and Stipa breviflora (Ma et al., 2008; Dai et al., 2014).

\subsection{Soil sampling and analysis}

Soil data were derived from two integrated surveys conducted in the native grasslands of Inner Mongolia. The first was an integrated soil survey conducted by the Chinese Academy of Sciences during 1963-1964 (Inner Mongolia and Ningxia Integrated Survey Team, Chinese Academy of Sciences, 1978). The soil sampling sites were determined on the basis of typical grassland and soil types, with the final selection made by visual inspection in the field. The soil types included aeolian soil, solonetz, black soil, brown pedocal, chernozem, castanozem, dark loessial soil, desert soil, loess soil, fluvo-aquic soil, and sierozem. A total of 163 soil sampling sites were identified in this soil survey. Information on each soil sampling site was collected, including geographical location, grassland type, land use type, soil genetic horizons, SOM content, and particle size distribution.

To identify the change in SOCD at temporal scales, we revisited the locations of the previous soil survey during the growing seasons of 2007 and 2011. It should be noted that we carefully compared each soil sampling site between the 1960s (the first soil survey in 1963-1964) and the 2010s (the second soil survey in 2007 and 2011) in terms of geographical location (longitude and latitude), topographical characteristics (elevation and slope), land use type, vegetation information and soil profile descriptions (e.g., soil type, horizon name and thickness). Thus, we identified 142 sampling sites that were matched with the original sampling sites regarding the profile descriptions, vegetation types, and land use types. Of these 142 soil sampling sites, only 122 sites were located in native grasslands in 1963; and, of these 122 soil sampling sites, 10 sites were subjected to tillage before the second soil survey in 2007. Finally, we selected 112 soil sampling sites that always remained within native grasslands during the period 1963-2011 in this study (Fig. 1).

During the soil surveys, soil pits were excavated with a spade to the depth of $1 \mathrm{~m}$ at each sampling site, and the coordinates and descriptions of soil genetic horizons of the A horizon (eluvial horizon) were recorded. Approximately 4-6 soil layers were set in each soil sampling site on the basis of soil genetic horizons. Three soil samples were taken in each soil layer and then mixed for testing gravel content, soil texture and SOC content. For details, soil samples were air-dried, microscopic roots were removed by sieving, and fine roots were picked out by employing the electrostatic method. The gravel content of the soil was determined as the proportions of the soil skeleton with diameters in the ranges of $1-3,3-5$, and $>5 \mathrm{~mm}$. The gravel 
fragment content $>2 \mathrm{~mm}$ was calculated from the proportion of the soil skeleton and the corresponding diameter range using an exponential function. Clay, sand and silt contents from the A horizon collected in the 2010s were obtained with a particle size analyzer (LS 13-320, Beckman Coulter, USA). The SOC content in both reference periods (i.e., 1960s and 2010s) was determined by the $\mathrm{K}_{2} \mathrm{Cr}_{2} \mathrm{O}_{7}-\mathrm{H}_{2} \mathrm{SO}_{4}$ wet oxidation method of Walkey-Black (Walkley and Black, 1934). For soil bulk density analysis, soil samples were collected using metal cylinders $\left(100 \mathrm{~cm}^{3}\right.$ in volume) at each soil sampling site, and then the samples were oven-dried at $105^{\circ} \mathrm{C}$ and weighed following the methods of Shi et al. (2012).

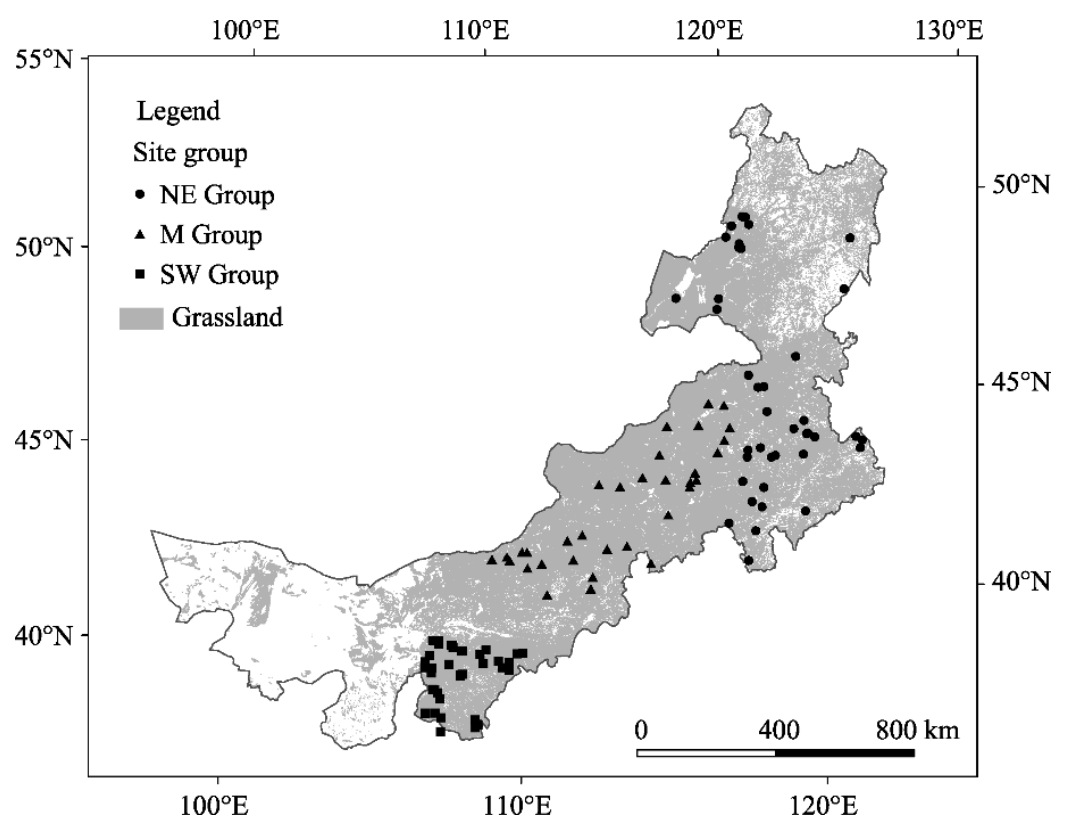

Fig. 1 Distribution of native grasslands and locations of soil sampling sites in Inner Mongolia Autonomous Region. It should be noted that soil sampling sites were classified into three geographical groups, i.e., northeastern (NE) Group, middle (M) Group and southwestern (SW) Group.

\subsection{Calculation of soil organic carbon density (SOCD)}

We calculated the SOCD based on the relationship between SOC content, soil bulk density and soil layer thickness (Eq. 1).

$$
\mathrm{SOCD}_{i}=\sum_{i=1}^{n}\left[\left(1-R_{v i}\right) \times \mathrm{BD}_{i} \times \mathrm{SOC}_{i} \times \mathrm{T}_{i}\right] / 100,
$$

where $\mathrm{SOCD}_{i}$ is the soil organic carbon density of the $i^{\text {th }}$ soil genetic horizon $\left(\mathrm{kg} \mathrm{C} / \mathrm{m}^{2}\right) ; n$ is the number of soil genetic horizons in the soil profile; $R_{v i}$ is the volume percentage of the fraction $>2$ $\mathrm{mm}(\%) ; \mathrm{BD}_{i}$ is the soil bulk density of the $i^{\text {th }}$ soil genetic horizon $\left(\mathrm{g} / \mathrm{cm}^{3}\right) ; \mathrm{SOC}_{i}$ is the soil organic carbon content of the $i^{\text {th }}$ soil genetic horizon $(\mathrm{g} / \mathrm{kg})$; and $\mathrm{T}_{i}$ is the thickness of the $i^{\text {th }}$ soil genetic horizon (cm). $R_{v i}$ can be calculated from the weight percentage of gravel fragment $\left(R_{m i}, \%\right)$ using Equation 2:

$$
R_{v i}=R_{m i} \times \mathrm{BD}_{i} / \mathrm{BD}_{r f}
$$

where $\mathrm{BD}_{r f}$ is the specific gravity of the gravel fraction $\left(\mathrm{g} / \mathrm{cm}^{3}\right)$. According to the method of Xie and $\mathrm{Li}(2012)$, we defined $\mathrm{BD}_{r f}$ as $2.1 \mathrm{~g} / \mathrm{cm}^{3}$ in this study based on the average bulky density of gravel.

\subsection{Explanatory factors and data collection}

We firstly collected 17 explanatory factors based on the sampling site selection criteria, and then excluded 7 explanatory factors according to the results of a multi-collinearity test. Thus, a total of 10 explanatory factors were selected in this study (Table 1). The original climate data were obtained from the National Meteorological Data Center of China (http://cdc.cma.gov.cn/home.do). We interpolated the climate data to $1 \mathrm{~km} \times 1 \mathrm{~km}$ grids using ordinary kriging method. Considering 
the lag effect of climate factors on the change in SOCD, we obtained a long-term climatic information in the form of 10-year averages for two periods (1954-1963 and 2000-2009). The changes in climate factors during the two periods were then calculated via subtraction. It should be noted that the climate factors were 10-year averages in our study because a previous research revealed that long-time periods (such as 20 or 30 years) had a negligible effect on SOC accumulation and modeling outcomes (Allen et al., 2013).

Table 1 Explanatory factors used to explain the change in SOCD (soil organic carbon density)

\begin{tabular}{|c|c|c|}
\hline Classification & Factor & Description \\
\hline \multirow[t]{5}{*}{ Climate } & $\triangle \mathrm{MAP}(\mathrm{mm})$ & $\begin{array}{l}\text { Change in mean annual precipitation (MAP) during the study period } \\
\left(\mathrm{MAP}_{2010 \mathrm{~s}}-\mathrm{MAP}_{1960 \mathrm{~s}}\right)\end{array}$ \\
\hline & $\Delta \mathrm{AMT}\left({ }^{\circ} \mathrm{C}\right)$ & $\begin{array}{l}\text { Change in annual mean temperature (AMT) during the study period } \\
\left(\mathrm{AMT}_{2010 \mathrm{~s}}-\mathrm{AMT}_{1960 \mathrm{~s}}\right)\end{array}$ \\
\hline & $\Delta \operatorname{ATT} 5\left({ }^{\circ} \mathrm{C}\right)$ & $\begin{array}{l}\text { Change in mean annual cumulative temperature } \geq 5^{\circ} \mathrm{C} \text { (ATT5) during the study period } \\
\left(\mathrm{ATT} 5_{2010 \mathrm{~s}}-\mathrm{ATT} 5_{1960 \mathrm{~s}} \text { ) }\right.\end{array}$ \\
\hline & $\triangle \mathrm{EVAP}(\mathrm{mm})$ & $\begin{array}{l}\text { Change in mean annual water surface evaporation (EVAP) during the study period } \\
\left(\mathrm{EVAP}_{2010 \mathrm{~s}}-\mathrm{EVAP}_{1960 \mathrm{~s}}\right)\end{array}$ \\
\hline & $\triangle \mathrm{MRH}(\%)$ & Change in mean relative humidity $(\mathrm{MRH})$ during the study period $\left(\mathrm{MRH}_{2010 \mathrm{~s}}-\mathrm{MRH}_{1960 \mathrm{~s}}\right)$ \\
\hline \multirow[t]{4}{*}{ Soil } & Clay $(\%)$ & Clay content of the A horizon \\
\hline & Sand $(\%)$ & Sand content of the A horizon \\
\hline & Silt $(\%)$ & Silt content of the A horizon \\
\hline & $\operatorname{SOCD}_{\text {mean }}\left(\mathrm{kg} \mathrm{C} / \mathrm{m}^{2}\right)$ & Mean value of natural logarithm-transformed $\mathrm{SOCD}_{1960 \mathrm{~s}}$ and $\mathrm{SOCD}_{2010 \mathrm{~s}}$ \\
\hline Grazing & $\Delta \mathrm{LD}\left(\mathrm{DSE} / \mathrm{hm}^{2}\right)$ & Change in livestock density (LD) during the study period $\left(\mathrm{LD}_{2010 \mathrm{~s}}-\mathrm{LD}_{1960 \mathrm{~s}}\right)$ \\
\hline
\end{tabular}

Note: DSE, dry sheep equivalent; A horizon, eluvial horizon.

The estimation of changes in soil texture during the reference periods was not calculated in this study because these changes are small with a wide error range and have a negligible effect on the change in SOCD in deeper soil layers (Ließ et al., 2012). The wide range of error in the changes of soil texture may occur because of the different determination methods applied in different periods. Therefore, the present study mainly focused on the contributions of different soil texture components to the change in SOCD.

The number of livestock in each county of Inner Mongolia in the two 10-year periods was derived from the rural socioeconomic data collected during annual surveys (Inner Mongolia Autonomous Region Bureau of Statistics, 1949-2017). The livestock density (LD), calculated as the average quantity of livestock divided by the grassland area, was used to represent the mean grazing intensity in the two reference periods. The unit measurement of LD was DSE (dry sheep equivalent, i.e., the amount of feed required by a two-year-old, $50 \mathrm{~kg}$ Merino sheep to maintain its weight) per hectare.

\subsection{Statistical modeling}

The distribution of SOCD in both reference periods followed a lognormal distribution. Therefore, the SOCD data were transformed into a natural logarithm form $(\log S O C D)$, and the log change in SOCD between the two periods was then subtracted (denoted as $\triangle \log S O C D$ ). Unless otherwise stated, all of the analyses were performed using R statistical software (R Core Team, 2017). The random forest method was used to identify the subset of non-redundant explanatory factors that had the greatest effect on the variability of the change in SOCD before the LMM was constructed. The random forest model can rapidly estimate the importance of each explanatory factor to the change in SOCD by reordering the value of each explanatory factor in turn. The explanatory factors with the greatest importance to the model can result in the greatest decrease in the accuracy of the model. The accuracy can be represented by the increase in the internal measure of the mean squared error (MSE) (Breiman, 2001). To obtain a robust ranking of the importance of the explanatory factors, we run the algorithm 500 times to account for the variability in importance rankings.

Considering the homogeneous group effect and the autocorrelations between the sampling sites in the broad study area, we divided the sampling sites into three geographical groups 
(northeastern (NE) Group, middle (M) Group and southwestern (SW) Group) according to the longitude and latitude of the sampling sites based on cluster analysis. The three geographical groups represented the northeast, middle and southwest of Inner Mongolia, respectively (Fig. 1).

LMM could provide information on both random and fixed effects related to the means and trends across multiple hierarchical organizational levels (Serneels et al., 2007). Based on the importance ranking of the explanatory factors determined by the random forest method, we fitted an LMM equation for each geographical group (Eq. 3):

$$
\Delta \operatorname{logSOCD}=\mathrm{Sand}+\Delta \mathrm{EVAP}+\Delta \mathrm{MAP}+\Delta \mathrm{AMT}+\Delta \mathrm{LD}+\Delta \mathrm{SOCD}_{\text {mean }}+(1 \mid \mathrm{Groups}) .
$$

The first six terms on the right side of Equation 3 are the fixed effects of the LMM and their definitions are shown in Table 1. It should be noted that although the $\triangle$ AMT (change in annual mean temperature (AMT)) had a low importance ranking according to the random forest analysis, we still used it in the model by considering the temperature sensitivity of SOM decomposition (Davidson and Janssens, 2006). Furthermore, to address the regression to the mean effect between the original SOCD and the change in SOCD, we used the mean SOCD value in the two reference periods (i.e., $\left.\left(\mathrm{SOCD}_{1960 \mathrm{~s}}+\mathrm{SOCD}_{2010 \mathrm{~s}}\right) / 2\right)$ in the $\mathrm{LMM}$, instead of the initial value (Oldham, 1962). The term 1 Groups represents the random effect of the LMM (i.e., the covariation of different geographical groups with change in SOCD). The LMM was fitted using a restricted maximum likelihood approach.

In this study, we introduced the absolute contribution rate (ACR) and relative contribution rate (RCR) of the explanatory factors to quantify the interpretability of each explanatory factor in relation to the change in SOCD based on LMM regression. The ACR and RCR can be calculated by Equations 4 and 5, respectively.

$$
\begin{aligned}
& \mathrm{ACR}_{i}=\frac{\mathrm{SS}_{i}}{\mathrm{SS}_{T}} \times 100 \%, \\
& \mathrm{RCR}_{i}=\frac{\mathrm{SS}_{i}}{\mathrm{SS}_{R}} \times 100 \%,
\end{aligned}
$$

where $\mathrm{ACR}_{i}$ is the contribution percentage of the $i^{\text {th }}$ explanatory factor to the total variation in the change in SOCD (\%); $\mathrm{RCR}_{i}$ is the contribution percentage of the $i^{\text {th }}$ explanatory factor to the explainable variation in the change in $\mathrm{SOCD}(\%) ; \mathrm{SS}_{T}$ is the sum of squares of the change in $\mathrm{SOCD} ; \mathrm{SS}_{R}$ is the regression sum of squares of the LMM; and $\mathrm{SS}_{i}$ is the partial sum of squares of the $i^{\text {th }}$ explanatory factor. We obtained the $\mathrm{SS}_{i}$ from the decomposition of the regression sum of squares based on the analysis of variance (ANOVA). Considering the robustness of the LMM, this study mainly focused on the quantitative explanatory power of the main effect of each fixed effect factor on the change in SOCD. In other words, interaction effects were not included in this study.

\section{Results}

\subsection{Change in SOCD}

The SOCD at the depth of $0-1 \mathrm{~m}$ in the native grasslands of Inner Mongolia decreased from 9.95 $( \pm 7.26) \mathrm{kg} \mathrm{C} / \mathrm{m}^{2}$ in the 1960 s to $8.12( \pm 7.36) \mathrm{kg} \mathrm{C} / \mathrm{m}^{2}$ in the $2010 \mathrm{~s}$ (decreased by $\left.18 \%\right)$. The change in SOCD exhibited a decreasing trend from the northeast to the southwest of Inner Mongolia, especially in the middle part (Fig. 2). The soil bulk density increased from $1.38( \pm 0.04)$ $\mathrm{g} / \mathrm{cm}^{3}$ in the $1960 \mathrm{~s}$ to $1.46( \pm 0.05) \mathrm{g} / \mathrm{cm}^{3}$ in the 2010s. The SW Group presented the largest increase of soil bulk density $\left(0.14 \mathrm{~g} / \mathrm{cm}^{3}\right.$; Table 2$)$. The spatial trend of change in SOC content was similar to that in SOCD. The SOC content was $0.46 \%$ lower in the $2010 \mathrm{~s}$ than in the $1960 \mathrm{~s}$. The differences in the changes of SOC content and bulk density indicated that the decrease in SOCD in the M Group was mainly related to the decrease of SOC content, while the decrease in SOCD in the SW Group was resulted from the differences in bulk density.

\subsection{Explanatory factor selection}

The rank of importance of the 10 explanatory factors returned by the random forest analysis is 

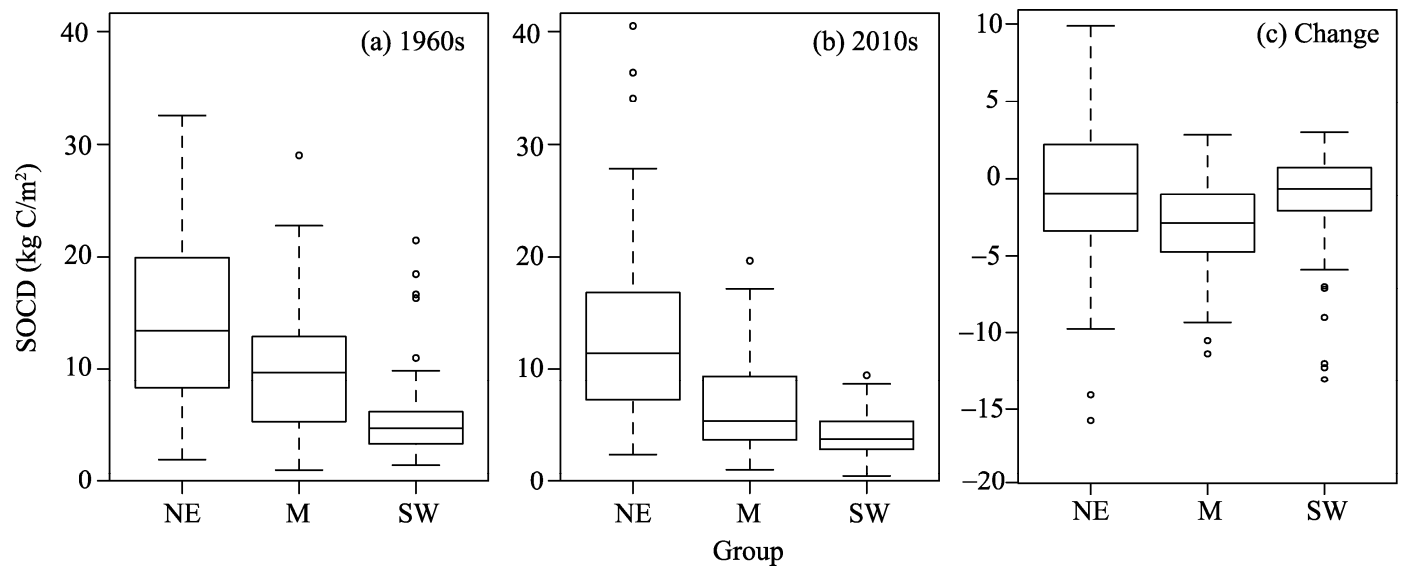

Fig. 2 SOCD (soil organic carbon density) in the 1960s (a) and 2010s (b) as well as the change in SOCD from the 1960 s to 2010 s (c) for each geographical group in the native grasslands of Inner Mongolia. The whiskers of the box and whisker plots denote the maximum value (less than or equal to the $3^{\text {rd }}$ quartile $+1.5 \mathrm{IQR}$ (interquartile range)) and the minimum value (greater than or equal to the $1^{\text {st }}$ quartile-1.5IQR), respectively. The circle points represent the values that greater than the $3^{\text {rd }}$ quartile $+1.5 \mathrm{IQR}$ or less than the $1^{\text {st }}$ quartile-1.5IQR.

Table 2 Changes in SOC (soil organic carbon) content and soil bulk density at the depth of 0-1 $\mathrm{m}$ in the native grasslands of Inner Mongolia from the 1960s to the 2010s

\begin{tabular}{|c|c|c|c|c|}
\hline \multirow{2}{*}{ Group } & \multicolumn{2}{|c|}{ Change in SOC content } & \multicolumn{2}{|c|}{ Change in soil bulk density } \\
\hline & Change $(\%)$ & Change rate $(\% / 100 \mathrm{a})$ & Change $\left(\mathrm{g} / \mathrm{cm}^{3}\right)$ & Change rate $\left(\mathrm{g} /\left(\mathrm{cm}^{3} \cdot 100 \mathrm{a}\right)\right)$ \\
\hline $\mathrm{NE}$ & 0.09 & 0.20 & 0.02 & 0.04 \\
\hline M & -1.37 & -2.80 & 0.07 & 0.14 \\
\hline SW & -0.09 & -0.20 & 0.14 & 0.28 \\
\hline Mean & -0.46 & -0.90 & 0.08 & 0.15 \\
\hline
\end{tabular}

Note: Soil sampling sites were classified into three geographical groups, i.e., northeastern (NE) Group, middle (M) Group and southwestern (SW) Group, representing the northeast, middle and southwest of Inner Mongolia, respectively.

shown in Figure 3. Six explanatory factors can be considered to influence $\triangle \operatorname{logSOCD}: \triangle \mathrm{EVAP}$ (change in mean annual water surface evaporation (EVAP)), $\triangle$ MAP (change in mean annual precipitation (MAP)), sand content, $\mathrm{SOCD}_{\text {mean }}$ (mean value of natural logarithm-transformed $\mathrm{SOCD}_{1960 \mathrm{~s}}$ and $\mathrm{SOCD}_{2010 \mathrm{~s}}$ ), $\triangle \mathrm{LD}$ (change in livestock density (LD)) and $\triangle \mathrm{AMT}$. Again, although the $\triangle \mathrm{AMT}$ had a low importance ranking according to the random forest analysis, we used it in the model by considering the temperature sensitivity of SOM decomposition.

The means and ranges of the six selected explanatory factors in each geographical group are shown in Table 3. Values of factors that correlated with temperature ( $\triangle E$ EAP and $\triangle \mathrm{AMT}$ ) and grazing $(\triangle \mathrm{LD})$ increased in the 2010s compared with those in the $1960 \mathrm{~s}$, whereas $\triangle \mathrm{MAP}$ decreased markedly over the past 50 years. $\mathrm{SOCD}_{\text {mean }}$ and $\triangle \mathrm{LD}$ exhibited the same decreasing trend as the change in SOCD from the northeast to the southwest of Inner Mongolia. Conversely, $\triangle$ MAP displayed an opposite spatial trend, i.e., showing an increasing trend from the northeast to the southwest.

\subsection{Contributions of explanatory factors to the change in SOCD}

Coefficients and variances for the random and fixed effects of the LMM are shown in Table 4. The variance of random effects indicated that $10 \%$ of the total variability in the change in SOCD existed between geographical groups. Therefore, we concluded that it is appropriate to use an LMM to analyze the change in SOCD. The change in SOCD was negatively correlated with $\triangle \mathrm{AMT}$ and $\triangle \mathrm{EVAP}$ and positively correlated with $\triangle \mathrm{MAP}$. The change in SOCD was significantly influenced by $\triangle \mathrm{EVAP}$ and soil texture.

Based on the LMM, we obtained the contributions of the explanatory factors to the change in 
SOCD using Equations 4 and 5 (Table 5). Climate factors ( $\triangle \mathrm{EVAP}, \triangle \mathrm{MAP}$, and $\triangle \mathrm{AMT}$ ) explained $9.84 \%$ and $51.57 \%$ of the total variation and explainable variation in the change in SOCD, respectively. Among the climate factors, $\triangle$ EVAP contributed the most to the change in SOCD whereas $\triangle \mathrm{AMT}$ contributed the least. Additionally, soil texture accounted for $3.94 \%$ and $20.63 \%$ of the total variation and explainable variation in the change in SOCD, respectively. The contribution of the variance explained by the grazing intensity was much lower than those explained by the other explanatory factors.

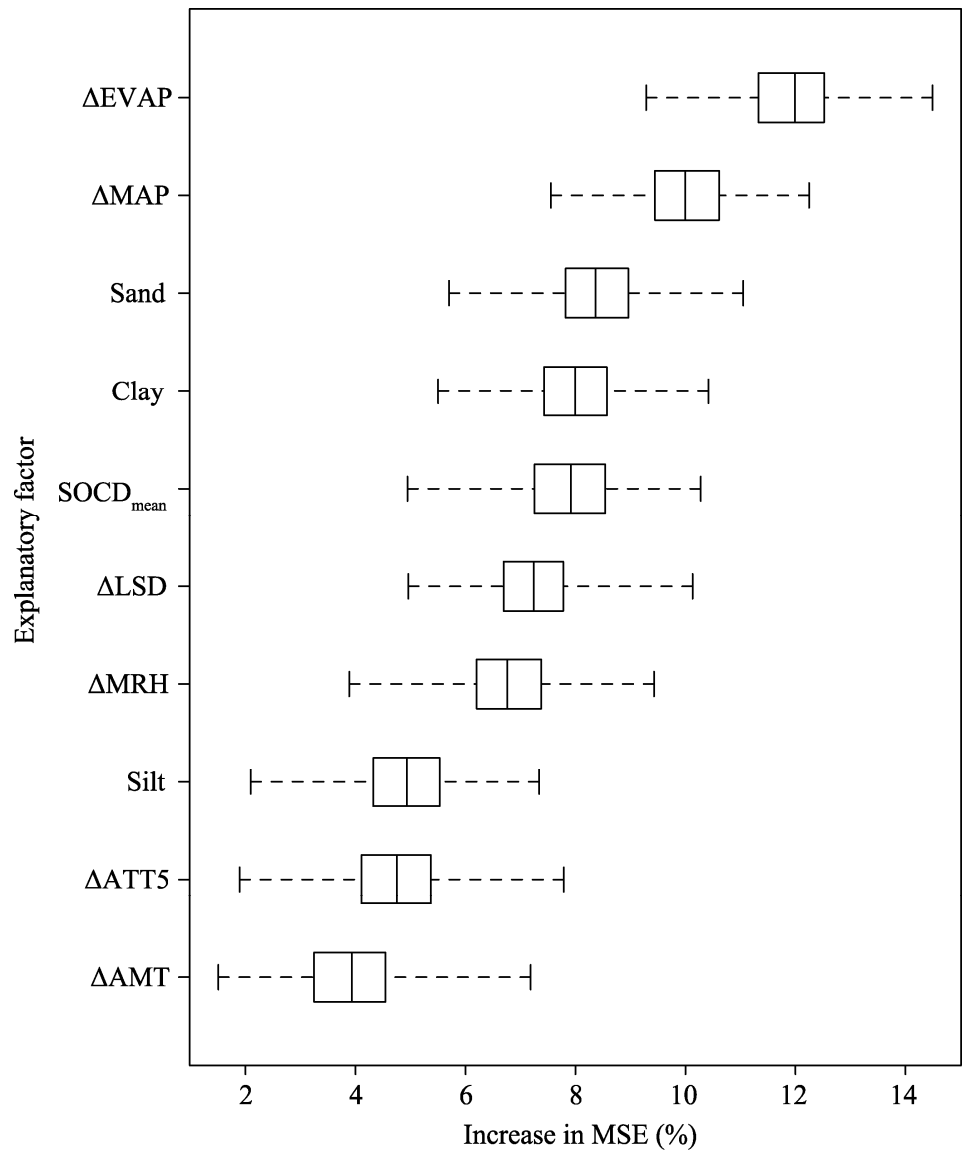

Fig. 3 Relative importance of the explanatory factors to the variation in the change in SOCD. The explanatory factors with the higher importance to the model can result in the higher decrease in the accuracy of the model (expressed as MSE (mean squared error)). The whiskers of the box-and-whisker plots denote data extremes and the importance of each factor decreases down the plot. $\triangle E V A P$, change in mean annual water surface evaporation; $\triangle \mathrm{MAP}$, change in mean annual precipitation; Sand, sand content of the A horizon (eluvial horizon); Clay, clay content of the A horizon; $\mathrm{SOCD}_{\text {mean }}$, mean value of natural logarithm-transformed $\mathrm{SOCD}_{1960 \text { s }}$ and $\mathrm{SOCD}_{2010 \text { s; }}$; $\Delta \mathrm{LD}$, change in livestock density; $\triangle \mathrm{MRH}$, change in mean relative humidity; Silt, silt content of the A horizon; $\Delta$ ATT5, change in mean annual cumulative temperature $\geq 5^{\circ} \mathrm{C} ; \Delta \mathrm{AMT}$, change in annual mean temperature.

Table 3 Means and ranges of the selected explanatory factors in each geographical group in the native grasslands of Inner Mongolia

\begin{tabular}{|c|c|c|c|c|c|c|c|}
\hline Group & $\begin{array}{c}\text { Number } \\
\text { of sites }\end{array}$ & $\begin{array}{c}\text { Sand } \\
(\%)\end{array}$ & $\begin{array}{l}\mathrm{MAP} \\
(\mathrm{mm})\end{array}$ & $\begin{array}{l}\text { EVAP } \\
(\mathrm{mm})\end{array}$ & $\begin{array}{c}\Delta \text { AMT } \\
\left({ }^{\circ} \mathrm{C}\right)\end{array}$ & $\begin{array}{c}\Delta \mathrm{LD} \\
\left(\mathrm{DSE} / \mathrm{hm}^{2}\right)\end{array}$ & $\begin{array}{c}\mathrm{SOCD}_{\text {mean }} \\
\left(\mathrm{kg} / \mathrm{m}^{2}\right)\end{array}$ \\
\hline NE & 40 & $\begin{array}{c}53.63 \\
(23.23-83.23)\end{array}$ & $\begin{array}{c}-52 \\
(-125-37)\end{array}$ & $\begin{array}{c}147 \\
(-134-406)\end{array}$ & $\begin{array}{c}1.53 \\
(0.06-2.72)\end{array}$ & $\begin{array}{c}0.81 \\
(0.15-2.62)\end{array}$ & $\begin{array}{c}14.21 \\
(2.21-35.55)\end{array}$ \\
\hline M & 34 & $\begin{array}{c}56.81 \\
(11.97-83.23)\end{array}$ & $\begin{array}{c}-60 \\
(-99-23)\end{array}$ & $\begin{array}{c}138 \\
(-9-278)\end{array}$ & $\begin{array}{c}1.68 \\
(0.96-2.33)\end{array}$ & $\begin{array}{c}0.33 \\
(-0.12-1.17)\end{array}$ & $\begin{array}{c}8.49 \\
(1.05-24.36)\end{array}$ \\
\hline SW & 38 & $\begin{array}{c}62.12 \\
(12.22-85.97) \\
\end{array}$ & $\begin{array}{c}-10 \\
(-86-148) \\
\end{array}$ & $\begin{array}{c}142 \\
(-326-531) \\
\end{array}$ & $\begin{array}{c}1.93 \\
(-0.45-5.27) \\
\end{array}$ & $\begin{array}{c}0.19 \\
(-0.22-0.80) \\
\end{array}$ & $\begin{array}{c}5.10 \\
(0.97-15.46) \\
\end{array}$ \\
\hline
\end{tabular}

Note: Means are listed in the front of the brackets and ranges are listed in the brackets. 
Table 4 Random and fixed effects of the linear mixed model for the natural log-transformed change in SOCD $(\triangle \log \mathrm{SOCD})$

\begin{tabular}{|c|c|c|c|c|}
\hline \multicolumn{5}{|c|}{ Random effects } \\
\hline Groups & Name & Variance & \multicolumn{2}{|c|}{ Standard deviation } \\
\hline Geographical group & Intercept & 0.022 & \multicolumn{2}{|c|}{0.148} \\
\hline Residual & & 0.189 & \multicolumn{2}{|c|}{0.435} \\
\hline \multicolumn{5}{|c|}{ Fixed effects } \\
\hline Parameter & Estimate & Standard error & $t$ value & $P$ value \\
\hline Intercept & 0.284 & 0.252 & -0.026 & 0.980 \\
\hline $\mathrm{SOCD}_{\text {mean }}$ & 0.046 & 0.071 & 0.641 & 0.523 \\
\hline Sand & -0.004 & 0.002 & -1.715 & 0.089 \\
\hline$\triangle \mathrm{MAP}$ & 0.001 & 0.001 & -0.212 & 0.833 \\
\hline$\triangle \mathrm{AMT}$ & -0.030 & 0.067 & 0.166 & 0.869 \\
\hline$\triangle \mathrm{EVAP}$ & -0.001 & 0.000 & -3.502 & 0.001 \\
\hline$\Delta \mathrm{LD}$ & 0.137 & 0.115 & 0.498 & 0.619 \\
\hline
\end{tabular}

Table 5 Contributions of the explanatory factors to the change in SOCD

\begin{tabular}{cccccc}
\hline Explanatory factor & $\mathrm{SS}_{i}$ & $\mathrm{SS}_{R}$ & $\mathrm{SS}_{T}$ & $\mathrm{ACR}(\%)$ & $\mathrm{RCR}(\%)$ \\
\hline SOCD $_{\text {mean }}$ & 0.12 & & & 0.48 & 2.53 \\
Sand & 0.98 & & & 3.94 & 20.63 \\
$\Delta \mathrm{MAP}$ & 0.07 & \multirow{4}{*}{4.75} & 24.90 & 0.28 & 1.47 \\
$\Delta \mathrm{AMT}$ & 0.02 & & 0.08 & 0.42 \\
$\Delta \mathrm{EVAP}$ & 2.36 & & 9.48 & 49.68 \\
$\Delta \mathrm{LSD}$ & 0.05 & & & 0.20 & 1.05 \\
\hline
\end{tabular}

Note: $\mathrm{SS}_{i}$, the partial sum of squares of the $i^{\text {th }}$ explanatory factor; $\mathrm{SS}_{R}$, the regression sum of squares of the LMM; $\mathrm{SS}_{T}$, the sum of squares of the change in SOCD; ACR, absolute contribution rate; RCR, relative contribution rate.

\section{Discussion}

Our findings revealed a SOCD loss of $1.83( \pm 4.57) \mathrm{kg} \mathrm{C} / \mathrm{m}^{2}$ in the native grasslands of Inner Mongolia during 1963-2011. This result was comparable to some previous observations in Inner Mongolia. For example, Wang et al. (2003) estimated a decreasing trend of SOCD from the 1960s to the 1980s in the grasslands of Inner Mongolia (from 2.15-5.00 to $0.00-2.15 \mathrm{~kg} \mathrm{C} / \mathrm{m}^{2}$ ) based on data from the first and second national soil surveys of China. Xie et al. (2007) detected a decrease of SOCD (decreased by $0.71 \mathrm{~kg} \mathrm{C} / \mathrm{m}^{2}$ ) in the grasslands of Inner Mongolia from the $1980 \mathrm{~s}$ to the 2000s using data from the Second National Soil Survey of China. These results indicated that the SOCD in the grasslands of Inner Mongolia decreased rapidly from the 1960s to the 1980s and decreased slowly from the 1980 s to the 2000 s.

In this study, we detected a significant negative correlation between the change in SOCD and the original SOCD $(r=-0.21, P<0.03)$, indicating that the carbon-rich soils tend to lose carbon. On the contrary, the carbon-poor soils generally tend to gain carbon. This phenomenon was identified through regression to the mean effect, which is a methodological bias that commonly occurs between the change and original values (Pearson, 1896; Chamberlain et al., 2010). Oldham (1962) suggested that the means of two measurements might be used, instead of the original values, to account for the fact that the samples were characterized by non-equivalent time intervals between two surveys (Lark et al., 2006). In this study, we introduced the natural

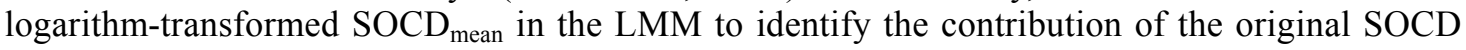
to the change in SOCD. Our results indicated that the original SOCD had a little effect on the change in SOCD, which explained only $0.48 \%$ and $2.53 \%$ of the total variation and explainable variation, respectively (Table 5). Thus, the significant negative correlation between the original SOCD and the change in SOCD is mainly due to the regression of the mean effect. In this study, we introduced an LMM to minimize the bias generated by spatial heterogeneity. To obtain a 
robust regression model, we mainly focused the LMM on the direct effects of the explanatory factors on the change in SOCD and did not consider the interactions or indirect effects of these factors, since insufficient data were available to support such a complex model. It should be noted that we used three geographical groups derived from the cluster analysis instead of grassland types as random effects in the LMM, because the classification of grassland types is a comprehensive result considering the climatic, geographical, biological, and ecological characteristics. Therefore, grassland types are not independent of the explanatory factors and cannot be the random effects in the LMM. The geographical groups are derived on the theory of spatial autocorrelation. The relationship between two sampling sites is correlated only with the distance between them, i.e., the closer the two sampling sites, the more similar the two sampling sites. Thus, the geographical groups are independent of the fixed factors.

Numerous studies have documented that climate change significantly influences SOC content at different spatial and temporal scales (Cao and Woodward, 1998; Fantappiè et al., 2011; Shangguan et al., 2012; Allen et al., 2013). For example, Fantappiè et al. (2011) proposed that a moderate or large decrease in MAP (decrease of $>2 \mathrm{~mm}$ ) and a moderate-to-large increase in AMT (increase of $>0.62^{\circ} \mathrm{C}$ ) generally had a stronger effect on the decrease in SOC content in meadows than in forests or arable land in Italy from 1961 to 2008. Climate factors related to soil moisture, such as precipitation and evaporation, which incorporate approximated the first-order factors, may be strongly related to the change in SOCD at a regional scale (Wynn et al., 2006; Allen et al., 2013). This study adds further evidence, as the direct effects of all explanatory factors explained about $15 \%$ of the total variation in the change in SOCD. The change in evaporation was the dominant explanatory factor on the change in SOCD, explaining $9.48 \%$ and $49.68 \%$ of the total variation and explainable variation, respectively (Table 5). The availability of water is mainly dependent on the rates of water input (precipitation) and output (evaporation). The amount of soil moisture output increases as evaporation increases. Then, the amount of water available for plant growth is limited and the rate of biomass input to soil is reduced, consequently decreasing the carbon flow transformed to the soil carbon pool (Wynn et al., 2006). In this study, the observed climate change-dominated SOCD dynamics should be considered spatially, as the sampling sites were distributed across a wide spatial range in Inner Mongolia. The decreases of SOCD in NE, M and SW groups were mainly driven by the changes in EVAP, MAP and AMT, respectively. These findings indicated that the decrease in SOCD dominated by climate factors could vary at regional scales.

As shown in Table 5, the contribution of the sand content to the change in SOCD ranked the second among the selected explanatory factors, explaining $3.94 \%$ and $20.63 \%$ of the total variation and explainable variation, respectively. According to our study, SOCD exhibited a decreasing trend in sandy soil and an increasing trend in clayey soil in the grasslands of Inner Mongolia. These findings verified that fine soil texture tends to protect organic matter while coarse soil texture tends to loss organic matter (Burke et al., 1989; Parton et al., 1993, 1995). Silver et al. (2000) demonstrated that the flow of carbon from slow-turnover SOM to passive SOM is inversely related to the sand content, and Wiesmeier et al. (2015) concluded that the capacity of soil carbon storage in semi-arid steppes depends on the silt and clay contents.

Issues regarding the effect of grazing on the SOC content are debated and no consensus has yet been reached (Frank et al., 1995; Reeder et al., 2004; Goidts et al., 2009; He et al., 2011). Generally speaking, grazing influences the SOC in a complex manner (Zou et al., 2007; Piñeiro et al., 2010; Butler-Lapointe, 2014; Pringle et al., 2014). In this study, the grazing density was found to have a little positive effect on the decrease in SOCD, which is in accordance with the findings of some previous studies conducted in Inner Mongolia (e.g., Zhao et al., 2007; Han et al., 2008; Steffens et al., 2008; Wiesmeier et al., 2009; Liu et al., 2012). Wiesmeier et al. (2009) determined the SOC stocks at two continuously grazed sites and two ungrazed (fenced and excluded) sites in steppe ecosystems dominated by L. chinensis and S. grandis in Inner Mongolia, and found that SOC stocks were significantly lower while bulk density was significantly higher in the topsoil layer $(0-4 \mathrm{~cm})$ at both continuously grazed sites. Steffens et al. (2008) sampled five sites with different grazing intensities (ranging from ungrazed site to heavily grazed site) at a depth of $0-4$ 
$\mathrm{cm}$ in a semi-arid steppe of Inner Mongolia, and found a significant lower SOC stock in the heavily grazed site while no significant differences in the remaining sites. In this study, $\Delta$ LD was observed to be positively correlated with the change in SOCD, which may be due to the large uncertainty associated with the determination of livestock grazing density or the strong correlations of the change in SOCD with climate factors and the original SOCD (Chan et al., 2010).

\section{Conclusions}

Based on two integrated soil survey datasets in the native grasslands of Inner Mongolia, we found a significant decrease of SOCD from the 1960 s to the 2010 s. The contributions of the explanatory factors (climate factors, soil texture, and grazing intensity) to the change in SOCD were quantified using a random forest model and a linear mixed model. The climate factors dominated the change in SOCD, especially the mean annual water surface evaporation, which explained approximately $10 \%$ and $50 \%$ of the total variation and explainable variation, respectively. Thus, climate may be the most critical factor in driving the SOCD dynamics in the temperate grasslands. Soil texture was the secondary controlling factor on the change in SOCD, especially the sand content, which explained about $4 \%$ and $21 \%$ of the total variation and explainable variation, respectively. The influence of grazing intensity in the change in SOCD was difficult to determine and only a small contribution was detected. To sum up, the results of this study have a profound significance for ecosystem management and conservation in the native grasslands of Inner Mongolia.

\section{Acknowledgments}

This study was financially supported from the National Natural Science Foundation of China (41471093), the Key Technologies Research and Development Program of China (2012BAC19B04), the International Science and Technology Cooperation Project of China (2012DFA31290), the Fundamental Research Funds for Central Non-profit Scientific Institution (1610132016033, 1610132016027), and the Special Funding for the Modern Agricultural Technology System from the Chinese Ministry of Agriculture (CARS-35-11). We gratefully acknowledge the Agricultural Data Center (http://www.agridata.cn) for data support.

\section{References}

Allen D E, Pringle M J, Bray S, et al. 2013. What determines soil organic carbon stocks in the grazing lands of north-eastern Australia? Soil Research, 51(8): 695-706.

Bai Y F, Wu J G, Clark C M, et al. 2012. Grazing alters ecosystem functioning and C:N:P stoichiometry of grasslands along a regional precipitation gradient. Journal of Applied Ecology, 49(6): 1204-1215.

Batjes N H. 2014. Total carbon and nitrogen in the soils of the world. European Journal of Soil Science, 65(1): 2-3.

Breiman L. 2001. Random forests. Machine Learning, 45(1): 5-32.

Burke I C, Yonker C M, Parton W J, et al. 1989. Texture, climate, and cultivation effects on soil organic matter content in U.S. grassland soils. Soil Science Society of America Journal, 53(3): 800-805.

Butler-Lapointe N. 2014. Grazing livestock to increase soil carbon and nitrogen. Natural Sciences Education, 43(1): 5-7.

Cao M K, Woodward F I. 1998. Dynamic responses of terrestrial ecosystem carbon cycling to global climate change. Nature, 393(6682): 249-252.

Chamberlain P M, Emmett B A, Scott W A, et al. 2010. No change in topsoil carbon levels of Great Britain, 1978-2007. Biogeosciences Discussions, 7(2): 2267-2311.

Chan K Y, Oates A, Li G D, et al. 2010. Soil carbon stocks under different pastures and pasture management in the higher rainfall areas of south-eastern Australia. Australian Journal of Soil Research, 48(1): 7-15.

Chen Q S, Li L H, Han X G, et al. 2004. Temperature sensitivity of soil respiration in relation to soil moisture in 11 communities of typical temperate steppe in Inner Mongolia. Acta Ecologica Sinica, 24(4): 831-836. (in Chinese)

Conforti M, Lucà F, Scarciglia F, et al. 2016. Soil carbon stock in relation to soil properties and landscape position in a forest ecosystem of southern Italy (Calabria region). CATENA, 144: 23-33.

Dai E F, Zhai R X, Ge Q S, et al. 2014. Detecting the storage and change on topsoil organic carbon in grasslands of Inner 
Mongolia from 1980s to 2010s. Journal of Geographical Sciences, 24(6): 1035-1046.

Davidson E A, Janssens I A. 2006. Temperature sensitivity of soil carbon decomposition and feedbacks to climate change. Nature, 440(7081): 165-173.

Fantappiè M, L'Abate G, Costantini E A C. 2011. The influence of climate change on the soil organic carbon content in Italy from 1961 to 2008. Geomorphology, 135(3-4): 343-352.

Frank A B, Tanaka D L, Hofmann L, et al. 1995. Soil carbon and nitrogen of Northern Great Plains grasslands as influenced by long-term grazing. Journal of Range Management, 48(5): 470-474.

Fujisaki K, Perrin A S, Desjardins T, et al. 2015. From forest to cropland and pasture systems: a critical review of soil organic carbon stocks changes in Amazonia. Global Change Biology, 21(7): 2773-2786.

Goidts E, Van Wesemael B. 2007. Regional assessment of soil organic carbon changes under agriculture in southern Belgium (1955-2005). Geoderma, 141(3-4): 341-354.

Goidts E, Van Wesemael B, Van Oost K. 2009. Driving forces of soil organic carbon evolution at the landscape and regional scale using data from a stratified soil monitoring. Global Change Biology, 15(12): 2981-3000.

Han G D, Hao X Y, Zhao M L, et al. 2008. Effect of grazing intensity on carbon and nitrogen in soil and vegetation in a meadow steppe in Inner Mongolia. Agriculture, Ecosystems \& Environment, 125(1-4): 21-32.

He N P, Zhang Y H, Yu Q, et al. 2011. Grazing intensity impacts soil carbon and nitrogen storage of continental steppe. Ecosphere, 2(1): art8, doi: 10.1890/ES10-00017.1.

Hu Q, Pan F F, Pan X B, et al. 2015. Spatial analysis of climate change in Inner Mongolia during 1961-2012, China. Applied Geography, 60: 254-260.

Inner Mongolia Autonomous Region Bureau of Statistics. 1949-2017. Rural socioeconomic data. http://www.nmgtj.gov.cn/nmgttj/index.htm.

Inner Mongolia and Ningxia Integrated Survey Team, Chinese Academy of Sciences. 1978. Soil Geography of Inner Mongolia and Western Part of North-East China. Beijing: Science Press, 1-354. (in Chinese)

Janitza S, Tutz G, Boulesteix A L. 2016. Random forest for ordinal responses: prediction and variable selection. Computational Statistics \& Data Analysis, 96: 57-73.

Lal R. 1999. World soils and the greenhouse effect. Global Change Newsletter, 37: 4-5.

Lal R. 2004. Soil carbon sequestration to mitigate climate change. Geoderma, 123(1-2): 1-22.

Lark R M, Bellamy P H, Kirk G J D. 2006. Baseline values and change in the soil, and implications for monitoring. European Journal of Soil Science, 57(6): 916-921.

Lefèvre R, Barré P, Moyano F E, et al. 2014. Higher temperature sensitivity for stable than for labile soil organic carbon-evidence from incubations of long-term bare fallow soils. Global Change Biology, 20(2): 633-640.

Li X J, Zhang X Z, Zhao Y P, et al. 2011. Dynamics of soil organic carbon in alpine meadow of Tibetan Plateau with CENTURY model. In: International Conference on Business Management and Electronic Information. Guangzhou, China: IEEE, 797-800.

Ließ M, Glaser B, Huwe B. 2012. Uncertainty in the spatial prediction of soil texture: Comparison of regression tree and random forest models. Geoderma, 170: 70-79.

Liu N, Zhang Y J, Chang S J, et al. 2012. Impact of grazing on soil carbon and microbial biomass in typical steppe and desert steppe of Inner Mongolia. PLoS ONE, 7(5): e36434.

Ma W H, Yang Y H, He J S, et al. 2008. Above- and belowground biomass in relation to environmental factors in temperate grasslands, Inner Mongolia. Science in China Series C: Life Sciences, 51(3): 263-270.

Mestdagh I, Sleutel S, Lootens P, et al. 2009. Soil organic carbon-stock changes in Flemish grassland soils from 1990 to 2000. Journal of Plant Nutrition and Soil Science, 172(1): 24-31.

Oldham P D. 1962. A note on the analysis of repeated measurements of the same subjects. Journal of Chronic Diseases, 15(10): 969-977.

Parton W J, Scurlock J M O, Ojima D S, et al. 1993. Observations and modeling of biomass and soil organic matter dynamics for the grassland biome worldwide. Global Biogeochemical Cycles, 7(4): 785-809.

Parton W J, Scurlock J M O, Ojima D S, et al. 1995. Impact of climate change on grassland production and soil carbon worldwide. Global Change Biology, 1(1): 13-22.

Pearson K. 1896. Mathematical contributions to the theory of evolution. --On a form of spurious correlation which may arise when indices are used in the measurement of organs. Proceedings of the Royal Society of London, 60: 489-498.

Piñeiro G, Paruelo J M, Oesterheld M, et al. 2010. Pathways of grazing effects on soil organic carbon and nitrogen. Rangeland Ecology \& Management, 63(1): 109-119.

Pringle M J, Allen D E, Phelps D G, et al. 2014. The effect of pasture utilization rate on stocks of soil organic carbon and total 
nitrogen in a semi-arid tropical grassland. Agriculture, Ecosystems \& Environment, 195: 83-90.

R Core Team. 2017. R: A language and environment for statistical computing. Vienna, Austria: R Foundation for Statistical Computing. https://www.R-project.org/.

Reeder J D, Schuman G E, Morgan J A, et al. 2004. Response of organic and inorganic carbon and nitrogen to long-term grazing of the shortgrass steppe. Environmental Management, 33(4): 485-495.

Schjønning P, Thomsen I K, Møberg J P, et al. 1999. Turnover of organic matter in differently textured soils: I. Physical characteristics of structurally disturbed and intact soils. Geoderma, 89(3-4): 177-198.

Serneels S, Linderman M, Lambin E F. 2007. A multilevel analysis of the impact of land use on interannual land-cover change in East Africa. Ecosystems, 10(3): 402-418.

Shangguan W, Dai Y J, Liu B Y, et al. 2012. A soil particle-size distribution dataset for regional land and climate modelling in China. Geoderma, 171-172: 85-91.

Shi Y, Baumann F, Ma Y, et al. 2012. Organic and inorganic carbon in the topsoil of the Mongolian and Tibetan grasslands: pattern, control and implications. Biogeosciences, 9(6): 2287-2299.

Silver W L, Neff J, McGroddy M, et al. 2000. Effects of soil texture on belowground carbon and nutrient storage in a lowland Amazonian forest ecosystem. Ecosystems, 3(2): 193-209.

Steffens M, Kölbl A, Totsche K U, et al. 2008. Grazing effects on soil chemical and physical properties in a semiarid steppe of Inner Mongolia (P.R. China). Geoderma, 143(1-2): 63-72.

Trumbore S E, Czimczik C I. 2008. Geology. An uncertain future for soil carbon. Science, 321(5895): 1455-1456.

Walkley A, Black I A. 1934. An examination of the degtjareff method for determining soil organic matter, and a proposed modification of the chromic acid titration method. Soil Science, 37(1): 29-38.

Wang S Q, Tian H Q, Liu J Y, et al. 2003. Pattern and change of soil organic carbon storage in China: 1960s-1980s. Tellus B: Chemical and Physical Meteorology, 55(2): 416-427.

Watson R T, Noble I R. 2002. Carbon and the science-policy nexus: the Kyoto challenge. In: Steffen W, Jäger J, Carson D J, et al. Challenges of a Changing Earth. Berlin, Heidelberg: Springer, 57-64.

Wiesmeier M, Steffens M, Kölbl A, et al. 2009. Degradation and small-scale spatial homogenization of topsoils in intensively-grazed steppes of Northern China. Soil and Tillage Research, 104(2): 299-310.

Wiesmeier M, Munro S, Barthold F, et al. 2015. Carbon storage capacity of semi-arid grassland soils and sequestration potentials in northern China. Global Change Biology, 21(10): 3836-3845.

Wynn J G, Bird M I, Vellen L, et al. 2006. Continental-scale measurement of the soil organic carbon pool with climatic, edaphic, and biotic controls. Global Biogeochemical Cycles, 20(1): GB1007.

Xie Y G, Li X. 2012. Methodology on rock fragments content evaluation: a review. Soils, 44(1): 17-22. (in Chinese)

Xie Z B, Zhu J G, Liu G, et al. 2007. Soil organic carbon stocks in China and changes from 1980s to 2000s. Global Change Biology, 13(9): 1989-2007.

Yang Y H, Fang J Y, Ma W H, et al. 2010. Soil carbon stock and its changes in northern China's grasslands from 1980s to 2000s. Global Change Biology, 16(11): 3036-3047.

Zhang H B, Yang G X, Huang Q, et al. 2011. Study on spatial scale transformation method of MODIS NDVI and NOAA NDVI in Inner Mongolia grassland. In: Li D L, Liu Y D, Chen Y Y. Computer and Computing Technologies in Agriculture IV. Berlin, Heidelberg: Springer, 658-666.

Zhao D S, Wu S H, Dai E F, et al. 2015. Effect of climate change on soil organic carbon in Inner Mongolia. International Journal of Climatology, 35(3): 337-347.

Zhao Y, Peth S, Krümmelbein J, et al. 2007. Spatial variability of soil properties affected by grazing intensity in Inner Mongolia grassland. Ecological Modelling, 205(1-2): 241-254.

Zou C J, Wang K Y, Wang T H, et al. 2007. Overgrazing and soil carbon dynamics in eastern Inner Mongolia of China. Ecological Research, 22(1): 135-142. 